\title{
Medication Adherence Among Women Undergoing Infertility Treatment: A Systematic Review
}

\author{
Diane E. Mahoney ${ }^{*}{ }^{\circledR}$, Cynthia L. Russell ${ }^{1}$, An-Lin Cheng ${ }^{2}$
}

\begin{abstract}
Objectives: The present study aimed to investigate medication adherence awareness among women undergoing infertility treatment. Materials and Methods: Several databases were searched including PubMed, Embase, CINAHL, PsycINFO, as well as ProQuest dissertations in order to collect the required data. In addition, based on the purpose of the study, English-language prospective, retrospective, observational, cross-sectional, quasi-experimental, and randomized controlled trial studies were selected which focused on medication adherence as a primary or secondary outcome in women with a diagnosis of infertility. Finally, critical appraisal for the quality of the study was assessed using Downs and Black Quality Checklist (1998) and STROBE guidelines. Results: Three studies conducted during 1993-2011 were analyzed. Further, sample sizes varied from 30 to 626 subjects with average rates of oral medication adherence ranging from $26 \%$ to $81 \%$ when used as the first-line therapy. More frequent daily dosing was associated with lower adherence rates. Based on the results, adherence was significantly lower when women were concerned about the side effects of medication adherence or reported 3 or more side effects rather than one or 2 cases. Furthermore, women with a body mass index of $<23 \mathrm{~kg} / \mathrm{m}^{2}$ or those who viewed medical treatment as convenient had higher adherence rates. It is noteworthy that none of the studies evaluated medication adherence during controlled ovarian hyperstimulation $(\mathrm{COH}) \mathrm{cycles}$, along with intrauterine insemination (IUI) or in vitro fertilization (IVF).

Conclusions: In general, rates of oral medication adherence are found suboptimal when used alone as first-line therapy. Accordingly, further studies regarding medication-taking behaviors are warranted in future research trials involving injection medications and $\mathrm{COH}$ cycles associated with IUI and IVF cycles in order to strengthen the clinical practice.

Keywords: Medication Adherence, Infertility, Fertility, In vitro Fertilization
\end{abstract}

\section{Introduction}

Infertility is a significant health problem for women, which is estimated to affect 80 million people worldwide $(1,2)$. In the United States, approximately $16 \%$ of the women of childbearing age are affected by infertility (3). In addition, many women undergo infertility treatment and are highly motived to become pregnant (4). Infertility treatment incorporates a variety of modalities to help women achieve pregnancy from minimally invasive to highly invasive procedures, along with fertility medication. According to American Society of Reproductive Medicine (5), treatment regimens can incorporate oral and/or injection medication for controlled ovarian hyper stimulation $(\mathrm{COH})$ in combination with or without intrauterine insemination (IUI), as well as assisted reproductive technology (ART) procedures such as vitro fertilization (IVF).

Women who tend to undergo any sort of infertility treatment are advised by healthcare providers to engage in self-managed lifestyle behaviors (e.g., healthy diet, adequate physical activity, smoking and marijuana cessation, and alcohol restrictions) and follow the prescribed protocols for fertility drugs in order to increase the chances of treatment success (6-10). However, adhering to lifestyle changes recommended by the health providers are found to be problematic $(9,11-14)$. In fact, negative lifestyle behaviors contributed to lower pregnancy rates for women undergoing IVF (15-20). This raises concerns regarding the extent to which women adhere to fertility medications while receiving the treatment.

Adherence to the prescribed medication is important for achieving the targeted health outcomes (21). Medication non-adherence is recognized as a prevalent global problem among the general population with adherence rates $50 \%$ on average, worldwide (22). Further, the medication-taking behavior of women receiving infertility treatment has not been adequately assessed. This is probably due to the belief that medication adherence is optimal in this patient population, particularly with high stakes procedures like IVF. In general, infertility treatment resulted in successful pregnancies for many women although most often after the repeated treatments. Although a woman's likelihood of pregnancy with infertility treatment decreases as she ages (35 years and older), younger women (under 35 years) undergoing assisted reproductive technology (ART) in the United States average $38 \%$ of pregnancy rates (U.S.) for each treatment cycle $(23,24)$. Infertility treatment 
regimens are frequently complex and can impede women's daily lives (25). Treatment cycles incorporate oral and/or injection routes. Medication schedules range from daily to multiple daily doses which are essentially very time sensitive (26). Failure to correctly take the medication during a treatment cycle decreases the likelihood of the medication which has its intended effect on reproductive hormones and ovarian follicular development, ultimately drives up the healthcare costs for the repeated treatments $(27,28)$.

Adherence can be defined as "the extent to which a person's behavior (i.e., taking medication, following a diet, and/or executing lifestyle changes) corresponds with the agreed recommendations from a health care provider" (22). In infertility literature, medication adherence is not well-defined during non-ART cycles such as IUI. With respect to ART, adherence is referred to the continuation of ART cycles including medication adherence recommended by the infertility provider until pregnancy is attained or there are provider suggestions to discontinue the treatment (29). Therefore, the existing research concentrated on ART cycle discontinuation rates rather than medication-taking patterns $(29,30)$.

Medication adherence has 3 distinct components including initiation, implementation, and discontinuation (21). Initiation is when a patient receives the first dose of a prescribed medication. Furthermore, Implementation refers to the degree to which the patient's actual medication usage corresponds to the prescribed medication regimen. Finally, discontinuation occurs when the next scheduled dose is omitted and no more medication is taken after this point. Thus, non-adherence occurs with late or no initiation of the prescribed medication, suboptimal implementation of the prescribed regimen, or early discontinuation (21).

Women with infertility are a population challenged by physical, psychological, emotional, and financial demands which accompany treatment, and some women report incorrect fertility medication-taking (27,31-33). However, researchers have not yet established a methodological process to monitor medication adherence with this group of women. Nor has there been attention directed toward factors to improve medication-taking behaviors in this population. Moreover, no prior review has explored the medication adherence patterns of women undergoing any type of infertility treatment. Accordingly, the current review aimed to determine the rates of medication adherence in women undergoing assistive reproductive treatment. The study questions included What are the rates of adherence to fertility drugs? and What are the predictors of and barriers to medication adherence among women receiving infertility treatment? Clinical interventions are believed to strengthen through identifying the patterns, predictors, and barriers related to medication adherence in women with infertility. Additionally, improving the quality of future research regarding medication adherence can have several advantages including improving clinical outcomes of the treatment, decreasing the likelihood of repeated failed cycles for non-adherence, and ultimately, reducing the overall expenditure of the health care.

\section{Methods}

Literature Search Strategy

A systematic review was conducted based on the standards of preferred reporting items for systematic reviews and meta-analysis (PRISMA) developed by Moher et al (34). To this end, a search was conducted to identify studies in which medication adherence was investigated among infertile women undergoing infertility treatment. Accordingly, several international databases were browsed including PubMed (1940-2017), Embase (1980-2017), CINAHL (1982-2017), PsycINFO (1806-2017), along with ProQuest dissertations. In addition, combinations of the following terms were used in this regard: "adherence", "compliance", "persistence", "concordance", "nonadherence", "non-adherence", "noncompliance", "non-compliance", "infertile*," "fertile*", "subfertile*”, "infecund*", "subfecund*”, "barren", "sterility", "infertility treatment", "fertility treatment", "in vitro fertilization", "intrauterine insemination", "pharmaceutic*", "prescript*”, "medical*”, "medicine", "medicines", "drug”, "drugs", "women", and "female".

\section{Inclusion/Exclusion Criteria}

Inclusion criteria were prospective, retrospective, observational, cross-sectional, quasi-experimental, and randomized controlled trial studies in which female participants aged 18-44 years were investigated who were diagnosed with infertility based on their medical record. Further, such studies were selected based on their results which were related to medication adherence as the primary or secondary outcome. Furthermore, participants aged 18-44 were included since this age range is representative of those women who seek infertility treatment (4). However, According to American Society of Reproductive Medicine (5), other women were excluded since they were neither a population seeking infertility services $(<18)$ nor were they suitable candidates for examination due to the reduction in their reproductive potential ( $>44)$ Moreover, non-English studies were excluded. The PRISMA Flow Diagram concerning the process of study selection is displayed in Figure 1. It should be noted that there was no need to obtain formal approval by an ethical review committee to conduct this review.

\section{Data Extraction}

The data extraction included author/year/design, purpose, sample/setting, intervention, measures, results, strengths, and limitations and was agreed upon by 2 independent reviewers (i.e., a DM and a CR) using a structured data collection sheet. A summary of the extracted data is presented in online Table S1 (see Supplementary file 1). 


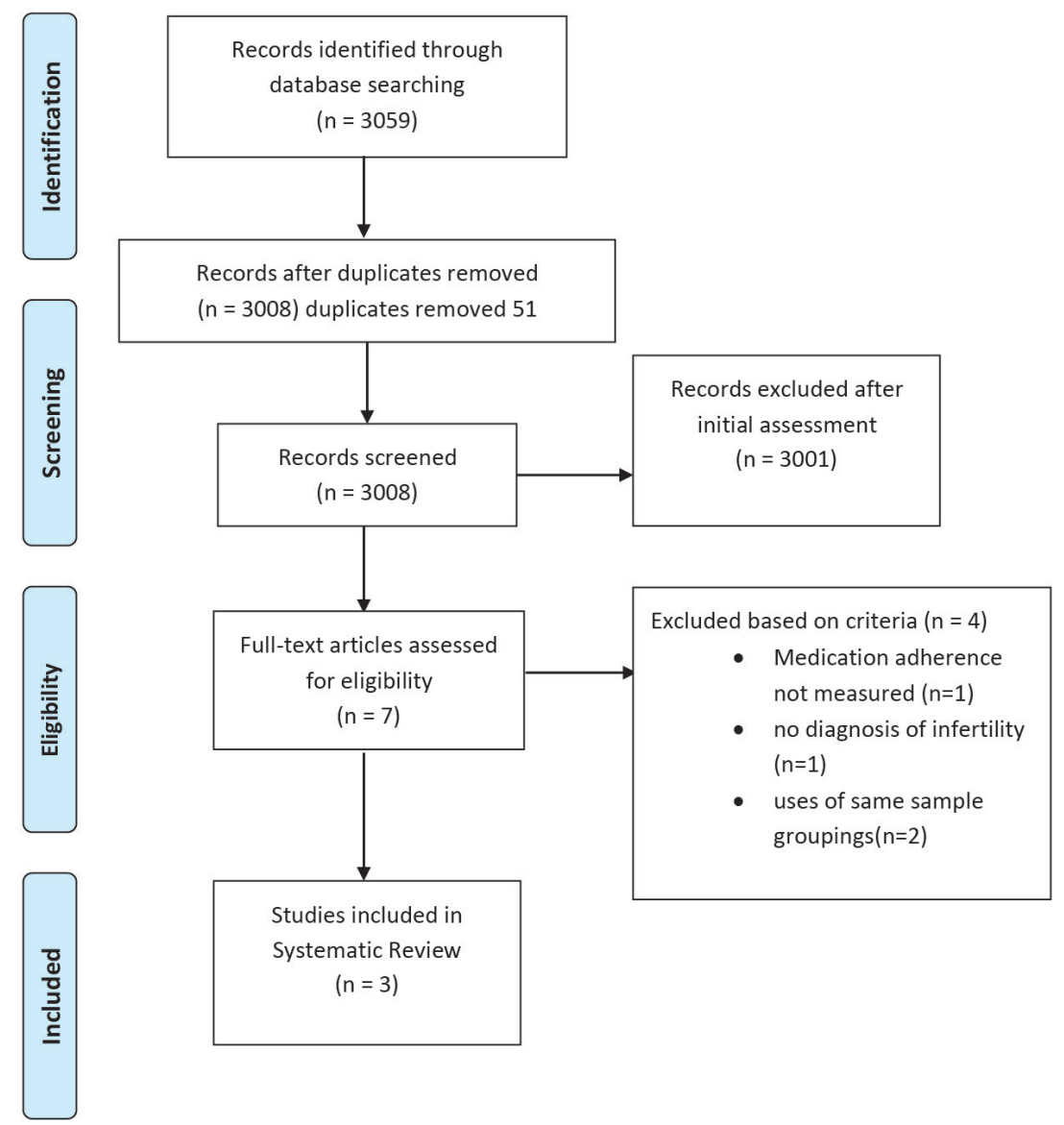

Figure 1. PRISMA Flow Diagram.

Quality Assessment

Critical appraisal was assessed by 2 independent reviewers (DM and CR) using the Downs and Black's (1998) checklist for evaluating the methodological quality of randomized and non-randomized studies and the guidelines of von Elm et al (35) as STrengthening the Reporting of OBservational studies in Epidemiology (STROBE). The STROBE guidelines were used to assess the quality of one study (36) since the Downs and Black criteria were not applicable for non-interventional studies. After the discussion, there was complete agreement between both reviewers respecting the quality of the study. The Downs and Black quality checklist contained 26 items spread across five subscales including reporting (9 items), external validity (3 items), bias (7 items), confounding (6 items), and power (1 item). Items were individually scored by a maximum total score of 32 indicating the highest quality. According to Downs and Black, this tool demonstrated a high internal consistency (KuderRichardson test $=0.89$ ), good test-retest reliability $(0.88)$, good criterion validity (0.89), and inter-rater reliability (0.75). Additionally, STROBE guidelines were designed as criteria for reporting the observational studies; however, these guidelines were used to assess the methodological rigor of published studies (38). Quality reporting of the individual studies included in this review is provided in online Table S2 (Supplementary file 1) and Table 1.

\section{Results}

Five studies, published during 1990-2011, met the inclusion criteria. However, 2 of these studies were excluded since the remaining 3 studies, conducted by the same authors (39-41), revealed strong similarities of sample characteristics (e.g., age, years of infertility, study location, intervention, and authors), raising suspicion of possible analysis of the same sample. Therefore, only the results of the most recent study of these 3 articles (41) were used in this review analysis in order to ensure the validity of study findings. The 2 earlier studies $(39,40)$ are shaded in online Table $S 1$ and are not included as individual study contributors in the analysis.

\section{Characteristics of Study Participants}

The total sample size included 777 participants. Individual study sample sizes ranged from 30 to 626 cases with mean ages ranging between 28 and 30 years. Only one study reported the participant race/ethnicity with the majority $(68 \%)$ being of Caucasian ancestry (42). In addition, mean body mass index (BMI) ranged from 24.0 to $36.6 \mathrm{~kg} / \mathrm{m}^{2}$ $(36,42)$. Further, the length of time attempting to conceive 
Table 1. STROBE Quality Assessment

\begin{tabular}{|c|c|c|c|}
\hline & Item No. & Recommendation & Li et al (2011) \\
\hline \multirow[t]{2}{*}{ Title and Abstract } & & (a) Indicating the design of the study with a commonly used term in the title or the abstract & Yes \\
\hline & 1 & $\begin{array}{l}\text { (b) Providing an informative and balanced summary of what was performed and what was } \\
\text { found, in the abstract }\end{array}$ & Yes \\
\hline \multicolumn{4}{|l|}{ Introduction } \\
\hline Background/rationale & 2 & Explaining the scientific background and rationale for the investigation being reported & Yes \\
\hline Objectives & 3 & Describing specific objectives including any prespecified hypotheses & No \\
\hline \multicolumn{4}{|l|}{ Methods } \\
\hline Study design & 4 & Presenting key elements of the study design early in the paper & Yes \\
\hline Setting & 5 & $\begin{array}{l}\text { Describing the setting, locations, and relevant dates including periods of recruitment, } \\
\text { exposure, follow-up, and data collection }\end{array}$ & Yes \\
\hline Participants & 6 & (a) Giving the eligibility criteria and the sources and methods of selection of participants & Yes \\
\hline Variables & 7 & $\begin{array}{l}\text { Clearly defining all the outcomes, exposures, predictors, potential confounders, and effect } \\
\text { modifiers. Giving diagnostic criteria, if applicable }\end{array}$ & No \\
\hline $\begin{array}{l}\text { Data } \\
\text { sources/measurement }\end{array}$ & $8^{*}$ & $\begin{array}{l}\text { Giving sources of data and details of methods of assessment (measurement) for each variable } \\
\text { of interest. Describing comparability of assessment methods if there is more than one group }\end{array}$ & Yes \\
\hline Bias & 9 & Describing any efforts to address the potential sources of bias & No \\
\hline Study size & 10 & Explaining how the study size was arrived at & No \\
\hline \multirow[t]{3}{*}{ Quantitative variables } & 11 & $\begin{array}{l}\text { Explaining how quantitative variables were handled in the analyses. If applicable, describing } \\
\text { which grouping was selected and why }\end{array}$ & No \\
\hline & & (a) Describing all the statistical methods including those used to control for confounding & Yes \\
\hline & & (b) Describing any methods used to examine subgroups and interactions & No \\
\hline \multirow[t]{3}{*}{ Statistical methods } & 12 & (c) Explaining how the missing data were addressed & No \\
\hline & & (d) If applicable, describing analytical methods taking into account the sampling strategy & No \\
\hline & & (e) Describing any sensitivity analyses & No \\
\hline \multicolumn{4}{|l|}{ Results } \\
\hline \multirow{3}{*}{ Participants } & \multirow{3}{*}{$13^{*}$} & $\begin{array}{l}\text { (a) Reporting the number of individuals at each stage of study (e.g., number of those } \\
\text { potentially eligible, examining the eligibility, confirming the eligible ones and including them in } \\
\text { the study, completing follow-up, and analyzing the collected data) }\end{array}$ & Yes \\
\hline & & (b) Giving reasons for non-participation at each stage & Yes \\
\hline & & (c) Considering the use of a flow diagram & No \\
\hline \multirow[t]{2}{*}{ Descriptive data } & \multirow[t]{2}{*}{$14^{*}$} & $\begin{array}{l}\text { (a) Giving the characteristics of the study participants (e.g., demographic, clinical, and social) } \\
\text { and information on exposures and potential confounders }\end{array}$ & Yes \\
\hline & & (b) Indicating the number of participants with missing data for each variable of interest & No \\
\hline Outcome data & $15^{*}$ & Reporting the number of outcome events or summary measures & Yes \\
\hline \multirow{3}{*}{ Main results } & \multirow{3}{*}{16} & $\begin{array}{l}\text { (a) Providing the unadjusted estimates and, if applicable, confounder-adjusted estimates and } \\
\text { their precision (e.g., } 95 \% \text { confidence interval). Making clear which confounders were adjusted } \\
\text { for and why they were included }\end{array}$ & Yes \\
\hline & & (b) Reporting the category boundaries when continuous variables were categorized & No \\
\hline & & $\begin{array}{l}\text { (c) If relevant, considering the translating estimates of the relative risk into absolute risk for a } \\
\text { meaningful time period }\end{array}$ & No \\
\hline Other analyses & 17 & $\begin{array}{l}\text { Reporting other analyses performed (e.g., analyses of subgroups and interactions, and } \\
\text { sensitivity analyses) }\end{array}$ & No \\
\hline \multicolumn{4}{|l|}{ Discussion } \\
\hline Key results & 18 & Summarizing the key results with reference to the study objectives & Yes \\
\hline Limitations & 19 & $\begin{array}{l}\text { Discussing the limitations of the study, taking into account the sources of potential bias or } \\
\text { imprecision. Discussing both direction and magnitude of any potential bias }\end{array}$ & Yes \\
\hline Interpretation & 20 & $\begin{array}{l}\text { Giving a cautious overall interpretation of the results considering objectives, limitations, } \\
\text { multiplicity of analyses, results from similar studies, and other relevant evidence }\end{array}$ & Yes \\
\hline Generalizability & 21 & Discussing the generalizability (external validity) of the study results & Yes \\
\hline \multicolumn{4}{|l|}{ Other information } \\
\hline Funding & 22 & $\begin{array}{l}\text { Giving the source of funding and the role of the funders for the present study and, if } \\
\text { applicable, for the original study on which the present article is based }\end{array}$ & No \\
\hline
\end{tabular}


varied from 1 year to more than 4 years $(36,41)$. Finally, most of the participants $(n=716)$ were infertile women with polycystic ovary syndrome (PCOS).

Study Location and Practice Setting

Studies were conducted in reproductive medicine/ infertility healthcare settings across the United States (42), Germany (41), and China (36). One study (36) addressed the type of payment for services, reporting that $88.9 \%$ of the participants were self-paid. In 2 other studies, 34.4\%$55 \%$ of women underwent prior infertility treatment while $31.1 \%-36.8 \%$ reported a previous pregnancy $(36,42)$.

\section{Study Purpose and Type}

In all the 3 studies, medication adherence was examined as first-line therapy. However, none of the studies assessed adherence associated with IUI or IVF cycles. Of course, 2 of the 3 studies $(41,42)$ shared a common purpose to examine the oral medication adherence while the remaining study (36) evaluated the combination of adherence to oral medication and recommendations for weight loss. Furthermore, one study (36) had a prospective, observational design while the other one (41) was prospective and randomized without a control group. Finally, the remaining study (42) was a randomized controlled trial with medication adherence which was examined retrospectively.

\section{Medication Adherence and Theoretical Framework}

Researchers in 2 of the 3 studies measured medication adherence using objective measures including medication event monitoring (41) and pill counts (42). The last study (36) measured medication adherence using a subjective measure (i.e., brief medication questionnaire). Moreover, the mean adherence rates ranged from $26 \%$ to $81 \%(36,42)$. Finally, there was no reporting on specific types of nonadherence (e.g., initiation, execution, and persistence) and none of the studies used a supporting theoretical framework.

Predictors and Barriers Related to Medication Adherence In 2 of 3 studies $(36,41)$, the researchers investigated possible factors which contributed to treatment nonadherence. The rate of medication adherence was significantly lower when participants were concerned about its side effects or reported 3 or more side effects instead of one or 2 cases $(36,41)$. Additionally, participants who had a $\mathrm{BMI}<23 \mathrm{~kg} / \mathrm{m}^{2}$ or who considered medical treatment to be convenient, had higher adherence rates (36). Eventually, the more frequent medication dosage per day led to a decrease in the adherence rates $(36,41,42)$.

\section{Discussion}

As the first one in its kind, the current systematic review was implemented to evaluate medication adherence among women undergoing infertility treatment. Only
3 studies met the criteria for inclusion in this review. Despite the extensive literature on adherence to lifestyle recommendations in women receiving infertility treatment, interest in studies on medication-taking behaviors has been overlooked $(6-10,13)$. The current review study revealed that the rates of adherence to first-line oral medication have a wide variation (26\%$81 \%)$. None of the studies assessed injection medication adherence nor medication-taking patterns during $\mathrm{COH}$ cycles associated with IUI and IVF. One could assume that women who take first-line oral medications fail to have as high stakes, namely, time investment, financial commitment, and medical risks compared to those women who undergo more advanced therapy, which can influence the adherence behaviors. However, this review provided evidence that the rates of oral medication adherence are consistent with general adherence rates in the literature which average $50 \%$.

One of the 3 studies in this review addressed a lifestyle factor combined with medication adherence behavior. Li et al examined treatment adherence to oral medications and weight loss recommendations within a subpopulation of infertile and obese women with PCOS (36). Obesity is a lifestyle management factor known to reduce infertility treatment success In addition, the findings of this review indicated that women who were not obese demonstrate better oral medication adherence $(19,43,44)$. Thus, obese women may be at a higher risk for multiple non-adherence behaviors (45). Further, the results of a recent study demonstrated that $40 \%$ of the women seeking infertility treatment actively engage in at least four unfavorable lifestyle-related behaviors which can negatively influence the reproductive outcomes (46). The present novel systematic review provided groundbreaking evidence that behaviors associated with adherence to oral infertility medication are unfavorable. The combination of medication nonadherence and negative lifestyle behaviors present a new conundrum that was not adequately addressed in previous literature for this population.

Furthermore, medication side effects and dosing frequency were observed as potential barriers to adherence $(36,41,42)$. Understanding potential barriers is considered important for optimizing adherence during infertility treatment cycles. As scientists continue to develop strategies for improving innovative reproductive procedures, technology can only be effective if medication protocols are followed. So far, to the best of our knowledge, the relationship between non-adherence behaviors regarding fertility medication and reproductive outcomes (i.e., canceled cycles, clinical pregnancies, and live birth rates) has not been well-documented in the literature. Markle et al found that the failure of women to correctly self-administer the injection medication leads to lower pregnancy rates (33).

Adherence to injection medication was measured in none of the studies from this review although these 
medications were problematic for other patient populations such as diabetic patients and those with multiple sclerosis $(47,48)$. Prescribed injectable regimens are commonly used in infertility treatment regimens. They are available in either single or multiple-dose vials requiring the client to withdraw the medication into a syringe prior to administration or administer the preloaded, multipledose, and self-injection pens. Women reported concerns about appropriate self-administering injections $(31,32)$. Some women made medication errors while they failed to report them to the infertility nurse or physician due to either considering the error insignificant or fearing of a negative reaction from the provider (32). Moreover, one study reported a case in which the client knowingly selfadministered less than the prescribed dosage of injection medication in order to save on the medication cost (27). The studies in this review did not examine the women's perspectives on taking fertility medication. However, discrepancies between healthcare providers and clients' perspectives on injection medication-taking behaviors were explored. Although the providers emphasized their concerns about the client's adherence to self-injection medications, they were surprised to find that women were taking incorrect medications, administering incorrect doses, and self-injecting medication incorrectly $(25,31)$.

The infertility healthcare environment, along with the prescribed medication protocols seems to overwhelm the women who undergo infertility treatment. Li et al reported that women who viewed their infertility treatment as convenient indicated higher rates of adherence compared to those who found the treatment inconvenient. Additionally, the burden of treatment was an ongoing problem for this patient population $(25,31,32)$. In fact, the inconvenience of frequent medication injections and the total length of treatment were regarded as central contributors to infertility treatment strain (31). In addition, the clinic environment was reported to worsen the treatment burden and affect the women's decisions to finish the treatment. Factors reported by these women included lack of continuity of care, negative attitudes of the health provider, ineffective communication with clinic staff, and insufficient time for asking their questions (25). A patient-centered care model obtained notable recognition as an indicator of high-quality infertility services (49-51). Thus, understanding the relationship between the quality of care and respective attitudes and behaviors toward medication adherence is of great importance.

Experts have begun an initiative to identify avenues for overcoming the barriers to infertility treatment by improving care for women both nationally and internationally (52). The US health insurance environment was an obstacle for gaining coverage for infertility services (53). Only 15 states passed the laws which required insurers to either cover or offer coverage for infertility diagnosis and treatment although some employers were provided with infertility coverage in non-mandated states (53). The American Society for Reproductive Medicine released a white paper on the current state of patient access to fertility care in the United States, which outlined several steps to improve access to care including infertility coverage (52). As this initiative moves forward, the urgency to redirect the focus on barriers to medication adherence may become a greater priority.

The literature regarding general medication adherence, the focus was on interventions in order to improve the quality of life, increase life expectancy, and reduce healthcare costs in chronic disease populations (54). In the United States, medication non-adherence was responsible for 125000 deaths and was estimated to well-exceed $\$ 100$ billion in healthcare expenditures annually (55). Further, the average cost per successful pregnancy and birth for women who underwent cycle-based infertility treatment was estimated over $\$ 48000$ (28). Non-adherence to fertility medication is not typically life-threatening although the fertility quality of life is considered a concern (56). Women's perceptions about their experience respecting infertility treatment are associated with the quality of life (51). However, the relationship between fertility quality of life and medication adherence behaviors has not been confirmed.

\section{Strengths and Limitations of the Study}

The unprecedented nature of the findings in this systematic review serves as a major strength by offering evidence which oral medication adherence, used as the first-line fertility therapy, can be more problematic than previously assumed by the clinicians and researchers. Two of the 3 studies used randomization into a group assignment, which minimizes the study bias and strengthens the findings. Furthermore, several limitations exist which need to be scrutinized. Studies not published in the English were excluded while those published in other languages may have an effect on the results of the current study. Moreover, the present review included a very small sample size and most study subjects were a subpopulation of infertile women with PCOS, which limits the generalizability of findings; only 3 studies were included for this review after 2 studies were excluded secondary to suspicion of having the same sample grouping. Additionally, the investigated studies were focused only on oral medications during the first-line therapy while not including injection medications nor medication adherence during IUI and IVF treatment cycles. In addition, one study examined medication adherence retrospectively. Although retrospective studies help establish the cause and effect relationships (i.e., contributory factors), the interpretation of the study findings is limited particularly when both selection and recall biases are present. Finally, different instruments were used to measure medication adherence, which could potentially confound the results 
and hinder the conclusions of the study.

\section{Implications of the Study}

Understanding the patterns of medication-taking is considered important since initiatives are in motion to broaden access to infertility services. Further, reproductive healthcare providers should reinforce the importance of following medication regimens. Furthermore, validating medication adherence in research trials including assisted reproductive therapies can better inform, cultivate, and perpetuate stronger innovative discoveries in reproduction science so as to strengthen the clinical practice.

\section{Recommendations for Future Research}

Future investigations are needed for exploring the women's patterns of medication adherence during IUI and IVF cycles. Moreover, insights on how healthcare delivery of infertility services (e.g., the degree of patientcenteredness, communication of the healthcare team, and availability of third-party reimbursement) impact medication-taking could reinforce continuity of care and therefore, medication adherence. The impact of infertility insurance coverage on the rates of medication adherence deserves further attention since healthcare costs continue to skyrocket. Additionally, determining whether the adherence rates differ across the regions of mandated infertility insurance coverage can be beneficial. In addition, the relationship between motivation to conceive and the likelihood of adherence is considered important if the theory-driven interventions are deemed necessary. Further, investigating how the quality of life and environmental factors influence medication adherence is of great significance, particularly when family support and treatment demands (e.g., psychological stress and anxiety, time off work for appointments, and treatment costs) can affect the decisions regarding the continuation of the services. Eventually, the standardization of medication adherence instruments is needed in future infertility research.

\section{Conclusions}

In general, the study findings confirm that the research regarding fertility medication adherence remains scarce. Accordingly, further research is timely and compelling. The state of the science on fertility medications is still underdeveloped when compared to general medication adherence research. Aligning medication-taking behaviors with reproductive outcomes (i.e., canceled cycles, clinical pregnancies, and live birth rates) during IUI and IVF cycles in future studies can help determine if the tailored interventions are involved. Furthermore, the rates of oral medication adherence are suboptimal when applied alone as the first-line therapy. Therefore, further investigation is required respecting medication-taking behaviors involving injection medications and controlled ovarian hyperstimulation cycles associated with IUI and IVF cycles to reinforce the clinical practice. A more extensive exploration into such unchartered territory answers the call of scientific inquiry through fostering innovation and versatility in order to advance human reproduction science.

\section{Conflict of Interests}

None declared.

\section{Ethical Issues}

Not applicable.

\section{Supplementary Data}

Supplementary file 1 contains Tables S1 and S2.

\section{References}

1. Rubin LR, Phillips A. Infertility and assisted reproductive technologies: Matters of reproductive justice. Santa Barbara, CA: Praeger; 2014.

2. Sharma R, Biedenharn KR, Fedor JM, Agarwal A. Lifestyle factors and reproductive health: taking control of your fertility. Reprod Biol Endocrinol. 2013;11:66. doi:10.1186/1477-7827-11-66

3. Thoma ME, McLain AC, Louis JF, et al. Prevalence of infertility in the United States as estimated by the current duration approach and a traditional constructed approach. Fertil Steril. 2013;99(5):1324-1331.e1321. doi:10.1016/j. fertnstert.2012.11.037

4. Chandra A, Copen CE, Stephen EH. Infertility service use in the United States: data from the National Survey of Family Growth, 1982-2010. Natl Health Stat Report. 2014(73):1-21.

5. American Society for Reproductive Medicine (ASRM). Age and Fertility: A guide for patients. ASRM; 2012.

6. Alvarez S. Do some addictions interfere with fertility? Fertil Steril. 2015;103(1):22-26. doi:10.1016/j. fertnstert.2014.11.008

7. Hassan MA, Killick SR. Negative lifestyle is associated with a significant reduction in fecundity. Fertil Steril. 2004;81(2):384-392. doi:10.1016/j.fertnstert.2003.06.027

8. Klonoff-Cohen H. Female and male lifestyle habits and IVF: what is known and unknown. Hum Reprod Update. 2005;11(2):179-203. doi:10.1093/humupd/dmh059

9. Rooney KL, Domar AD. The impact of lifestyle behaviors on infertility treatment outcome. Curr Opin Obstet Gynecol. 2014;26(3):181-185. doi:10.1097/gco.0000000000000069

10. Zarinara A, Zeraati H, Kamali K, Mohammad K, Shahnazari P, Akhondi MM. Models Predicting Success of Infertility Treatment: A Systematic Review. J Reprod Infertil. 2016;17(2):68-81.

11. Domar AD, Conboy L, Denardo-Roney J, Rooney KL. Lifestyle behaviors in women undergoing in vitro fertilization: a prospective study. FertilSteril.2012;97(3):697701.e691. doi:10.1016/j.fertnstert.2011.12.012

12. Domar AD, Rooney KL, Milstein M, Conboy L. Lifestyle habits of 12,800 IVF patients: Prevalence of negative lifestyle behaviors, and impact of region and insurance coverage. Hum Fertil (Camb). 2015;18(4):253-257. doi:10. 3109/14647273.2015.1071881 
13. Gormack AA, Peek JC, Derraik JG, Gluckman PD, Young NL, Cutfield WS. Many women undergoing fertility treatment make poor lifestyle choices that may affect treatment outcome. Hum Reprod. 2015;30(7):1617-1624. doi:10.1093/humrep/dev094

14. Schilling K, Toth B, Rosner S, Strowitzki T, Wischmann T. Prevalence of behaviour-related fertility disorders in a clinical sample: results of a pilot study. Arch Gynecol Obstet. 2012;286(5):1307-1314. doi:10.1007/s00404-0122436-x

15. Kasum M, Oreskovic S, Cehic E, Lila A, Ejubovic E, Soldo D. The role of female obesity on in vitro fertilization outcomes. Gynecol Endocrinol. 2018;34(3):184-188. doi:1 0.1080/09513590.2017.1391209

16. Klonoff-Cohen H, Lam-Kruglick P, Gonzalez C. Effects of maternal and paternal alcohol consumption on the success rates of in vitro fertilization and gamete intrafallopian transfer. Fertil Steril. 2003;79(2):330-339.

17. Klonoff-Cohen HS, Natarajan L, Chen RV. A prospective study of the effects of female and male marijuana use on in vitro fertilization (IVF) and gamete intrafallopian transfer (GIFT) outcomes. Am J Obstet Gynecol. 2006;194(2):369376. doi:10.1016/j.ajog.2005.08.020

18. Klonoff-Cohen H, Natarajan L, Marrs R, Yee B. Effects of female and male smoking on success rates of IVF and gamete intra-Fallopian transfer. Hum Reprod. 2001;16(7):13821390.

19. Rittenberg V, Seshadri S, Sunkara SK, Sobaleva S, OtengNtim E, El-Toukhy T. Effect of body mass index on IVF treatment outcome: an updated systematic review and meta-analysis. Reprod Biomed Online. 2011;23(4):421-439. doi:10.1016/j.rbmo.2011.06.018

20. Rossi BV, Berry KF, Hornstein MD, Cramer DW, Ehrlich S, Missmer SA. Effect of alcohol consumption on in vitro fertilization. Obstet Gynecol. 2011;117(1):136-142. doi:10.1097/AOG.0b013e31820090e1

21. Vrijens B, De Geest S, Hughes DA, et al. A new taxonomy for describing and defining adherence to medications. $\mathrm{Br}$ J Clin Pharmacol. 2012;73(5):691-705. doi:10.1111/j.13652125.2012.04167.x

22. Sabate E. Adherence to long-term therapies: evidence for action. Geneva: World Health Organization; 2003.

23. Society for Assisted Reproductive Technology (SART). Success rates 2016. http://www.sart.org/SART_Success_ Rates/. Published 2016.

24. National Center for Chronic Disease Prevention and Health Promotion. Assisted Reproductive Technology: National Summary Report. https://www.cdc.gov/art/ pdf/2015-report/ART-2015-National-Summary-Report. pdf. Published 2015.

25. Boivin J, Domar AD, Shapiro DB, Wischmann TH, Fauser BC, Verhaak C. Tackling burden in ART: an integrated approach for medical staff. Hum Reprod. 2012;27(4):941950. doi:10.1093/humrep/der467

26. Smith C, Grimm M, Schwegel M. Treatment of infertility in women. J Am Pharm Assoc (2003). 2012;52(4):e27-42. doi:10.1331/JAPhA.2012.12044

27. Noorhasan DJ, McCulloh DH, Cho M, McGovern PG. Follicle-stimulating hormone levels and medication compliance during in vitro fertilization. Fertil Steril. 2008;90(5):2013.e2011-2013. doi:10.1016/j. fertnstert.2008.04.072

28. Katz P, Showstack J, Smith JF, et al. Costs of infertility treatment: results from an 18-month prospective cohort study. Fertil Steril. 2011;95(3):915-921. doi:10.1016/j. fertnstert.2010.11.026

29. Gameiro S, Verhaak CM, Kremer JA, Boivin J. Why we should talk about compliance with assisted reproductive technologies (ART): a systematic review and metaanalysis of ART compliance rates. Hum Reprod Update. 2013;19(2):124-135. doi:10.1093/humupd/dms045

30. Gameiro S, Boivin J, Peronace L, Verhaak CM. Why do patients discontinue fertility treatment? A systematic review of reasons and predictors of discontinuation in fertility treatment. Hum Reprod Update. 2012;18(6):652669. doi:10.1093/humupd/dms031

31. Brod M, Verhaak CM, Wiebinga CJ, Gerris J, Hoomans EH. Improving clinical understanding of the effect of ovarian stimulation on women's lives. Reprod Biomed Online. 2009;18(3):391-400.

32. Huisman D, Raymakers X, Hoomans EH. Understanding the burden of ovarian stimulation: fertility expert and patient perceptions. Reprod Biomed Online. 2009;19 Suppl 2:5-10.

33. Markle RL, King PJ, Martin DB, Kutteh WH, Ke RW. Characteristics of successful human chorionic gonadotropin (hCG) administration in assisted reproduction. Fertil Steril. 2002;78:S71-s72. doi:10.1016/S0015-0282(02)03567-7

34. Moher D, Liberati A, Tetzlaff J, Altman DG. Preferred reporting items for systematic reviews and meta-analyses: the PRISMA statement. Ann Intern Med. 2009;151(4):264269, w264.

35. von Elm E, Altman DG, Egger M, Pocock SJ, Gotzsche PC, Vandenbroucke JP. The Strengthening the Reporting of Observational Studies in Epidemiology (STROBE) statement: guidelines for reporting observational studies. J Clin Epidemiol. 2008;61(4):344-349. doi:10.1016/j. jclinepi.2007.11.008

36. Li S, He A, Yang J, Yin T, Xu W. A logistic regression analysis of factors related to the treatment compliance of infertile patients with polycystic ovary syndrome. J Reprod Med. 2011;56(7-8):325-332.

37. Downs SH, Black N. The feasibility of creating a checklist for the assessment of the methodological quality both of randomised and non-randomised studies of health care interventions. J Epidemiol Community Health. 1998;52(6):377-384.

38. Matteson ML, Russell CL. Systematic review of continuous self-improvement interventions. Clin Nurs Stud. 2013;1(1):10-25. d:10.5430/cns.v1n1p10

39. Kruse W, Eggert-Kruse W, Rampmaier J, Runnebaum B, Weber E. Compliance with short-term high-dose ethinyl oestradiol in young patients with primary infertility. New insights from the use of electronic devices. Agents Actions Suppl. 1990;29:105-115.

40. Kruse W, Eggert-Kruse W, Rampmaier J, Runnebaum B, Weber E. Dosage frequency and drug-compliance behaviour--a comparative study on compliance with a medication to be taken twice or four times daily. Eur J Clin Pharmacol. 1991;41(6):589-592. doi:10.1007/bf00314990

41. Kruse W, Eggert-Kruse W, Rampmaier J, Runnebaum B, Weber E. Compliance and adverse drug reactions: a prospective study with ethinylestradiol using continuous compliance monitoring. Clin Investig. 1993;71(6):483-487.

42. McGovern PG, Carson SA, Barnhart HX, et al. Medication adherence and treatment success in the National Institute 
of Child Health and Human Development-Reproductive Medicine Network's Pregnancy in Polycystic Ovary Syndrome Trial. Fertil Steril. 2008;90(4):1283-1286. doi:10.1016/j.fertnstert.2007.09.004

43. Bellver J, Busso C, Pellicer A, Remohi J, Simon C. Obesity and assisted reproductive technology outcomes. Reprod Biomed Online. 2006;12(5):562-568.

44. Pinborg A, Gaarslev C, Hougaard CO, et al. Influence of female bodyweight on IVF outcome: a longitudinal multicentre cohort study of 487 infertile couples. Reprod Biomed Online. 2011;23(4):490-499. doi:10.1016/j. rbmo.2011.06.010

45. Mutsaerts MA, Kuchenbecker WK, Mol BW, Land JA, Hoek A. Dropout is a problem in lifestyle intervention programs for overweight and obese infertile women: a systematic review. Hum Reprod. 2013;28(4):979-986. doi:10.1093/ humrep/det026

46. Piche ML, Babineau V, Robitaille J, Lachance E, Ruchat SM. Lifestyle-Related Factors Associated with Reproductive Health in Couples Seeking Fertility Treatments: Results of A Pilot Study. Int J Fertil Steril. 2018;12(1):19-26. doi:10.22074/ijfs.2018.5135

47. Capoccia K, Odegard PS, Letassy N. Medication adherence with diabetes medication: a systematic review of the literature. Diabetes Educ. 2016;42(1):34-71. doi:10.1177/0145721715619038

48. Giovannoni G, Southam E, Waubant E. Systematic review of disease-modifying therapies to assess unmet needs in multiple sclerosis: tolerability and adherence. Mult Scler. 2012;18(7):932-946. doi:10.1177/1352458511433302

49. Gameiro S, Canavarro MC, Boivin J. Patient centred care in infertility health care: direct and indirect associations with wellbeing during treatment. Patient Educ Couns.
2013;93(3):646-654. doi:10.1016/j.pec.2013.08.015

50. Huppelschoten AG, Nelen WL, Westert GP, van Golde RJ, Adang EM, Kremer JA. Improving patient-centredness in partnership with female patients: a cluster RCT in fertility care. Hum Reprod. 2015;30(5):1137-1145. doi:10.1093/ humrep/dev041

51. Aarts JW, Huppelschoten AG, van Empel IW, et al. How patient-centred care relates to patients' quality of life and distress: a study in 427 women experiencing infertility. Hum Reprod. 2012;27(2):488-495. doi:10.1093/humrep/ der386

52. American Society for Reproductive Medicine (ASRM). White paper: Access to care summit. http://www.asrm.org/ globalassets/asrm/asrm-content/news-and-publications/ news-and-research/press-releases-and-bulletins/pdf/ atcwhitepaper.pdf. Published 2015.

53. National Conference of State Legislatures (NCSL). State laws related to coverage for infertility treatment http:// www.ncsl.org/research/health/insurance-coverage-forinfertility-laws.aspx. Published 2014.

54. Costa E, Giardini A, Savin M, et al. Interventional tools to improve medication adherence: review of literature. Patient Prefer Adherence. 2015;9:1303-1314. doi:10.2147/ppa. s87551

55. Viswanathan $\mathrm{M}$, Golin $\mathrm{CE}$, Jones $\mathrm{CD}$, et al. Interventions to improve adherence to self-administered medications for chronic diseases in the United States: a systematic review. Ann Intern Med. 2012;157(11):785-795. doi:10.7326/00034819-157-11-201212040-00538

56. Boivin J, Takefman J, Braverman A. The fertility quality of life (FertiQoL) tool: development and general psychometric properties. Hum Reprod. 2011;26(8):2084-2091.

(c) 2019 The Author (s); This is an open-access article distributed under the terms of the Creative Commons Attribution License (http://creativecommons.org/licenses/by/4.0), which permits unrestricted use, distribution, and reproduction in any medium, provided the original work is properly cited. 